\title{
Reflexão sobre Autonomia no Doente Mental: Aspectos Ético -Legais
}

\section{Reflection on Autonomy in the Mentally Ill: Ethical and Legal Aspects}

DOI: $10.46919 / \operatorname{archv2n6-003~}$

Recebimento dos originais: 01/06/2021

Aceitação para publicação: 31/07/2021

Maria Helena Rodrigues

Licenciada em Enfermagem, Enfermeira

Gestora do Departamento de Saúde Mental e Psiquiatria, Enfermeira Especialista Enfermagem de Saúde Mental e Psiquiátrica Hospital de Guimarães, Guimarães - Portugal

E-mail: helenarodrigues@hospitaldeguimaraes.min-saude.pt

\section{Elvira Ferreira}

Mestre em ética Enfermeira Especialista em Enfermagem de Saúde Mental e Psiquiátrica, Hospital de Guimarães , Guimarães-Portugal

E-mail: elviraferreira@ hospitaldeguimaraes.min-saude.pt

\section{Carmen Martins}

Licenciatura em Enfermagem

Hospital de Guimarães , Guimarães - Portugal

E-mail: carmenmartins@ @ospitaldeguimaraes.min-saude.pt

\section{Teresa Pereira}

Licenciatura em enfermagem, Hospital de Guimarães, Guimarães - Portugal

E-mail: mariateresapereira@ hospitaldeguimaraes.min-saude.pt

\section{Leonel Fernandes}

Mestre com Especialidade em Enfermagem de Saúde Mental e Psiquiátrica, Agrupamento de Centros de Saúde Braga - Unidade de Cuidados na Comunidade Assucena Lopes Teixeira , Braga - Portugal

E-mail: lgfernandes@arsnorte.min-saude.pt

\section{RESUMO}

São vários os significados que podemos atribuir à autonomia, variando de acordo com o olhar de quem se propõe estudá-la, ou como quer respeitá-la nas pessoas. De uma forma mais abrangente, a pessoa autónoma é aquela que tem liberdade de pensamento, livre de coações internas ou externas, para escolher entre as opções que lhe são apresentadas. A pessoa com doença mental pode ter a sua autonomia comprometida de forma transitória ou permanente, podendo este comprometimento variar de acordo com o grau de gravidade da doença.

$\mathrm{O}$ enfermeiro, num encontro face a face com a pessoa com patologia psiquiátrica, procura restabelecer a ordem perturbada, possibilitando a lucidez de pensamento, domínio dos sentimentos e afirmação de uma vontade livre, de forma a favorecer a confiança em si mesmo e o crescimento em termos de autonomia. Ajudar a pessoa a descobrir um sentido realizador para a sua vida, intervir na melhoria da sua qualidade, e promover a sua autonomia são as principais tarefas do enfermeiro de saúde mental, tendo sempre presente que o doente é o primeiro agente do seu processo terapêutico. 
Algumas limitações do direito de autonomia do doente são justificadas no período em que as condições mentais alteram a sua capacidade de tomar decisões. Porém, logo que se recuperem, devemos ajudar para que ele próprio seja o decisor nas suas escolhas e opções.

Por detrás do condicionalismo da doença mental existe uma pessoa em busca de sentido e de liberdade, que lança a toda a equipa variados desafios.

Pretendemos com este trabalho reflectir sobre a nossa prática diária, de forma a promover a autonomia no acto de cuidar e, salvaguardar o respeito pela dignidade da pessoa doente, utilizando a competência humanizada e a atenção holística adequada a cada caso.

Palavras chave: Autonomia, direito, doente, ético-legais

\begin{abstract}
There are several meanings that we can attribute to autonomy, varying according to the look of those who propose to study it, or how they want to respect it in people. In a broader sense, an autonomous person is one who has freedom of thought, free from internal or external coercion, to choose among the options presented to him or her. The person with mental illness may have their autonomy compromised temporarily or permanently, and this compromise may vary according to the severity of the illness.

The nurse, in a face-to-face encounter with the person with psychiatric pathology, seeks to reestablish the disturbed order, enabling clarity of thought, mastery of feelings, and affirmation of a free will, in order to foster self-confidence and growth in terms of autonomy.

Helping people discover a fulfilling meaning to their lives, intervening to improve their quality of life, and promoting their autonomy are the main tasks of the mental health nurse, always keeping in mind that the patient is the first agent of his therapeutic process.

Some limitations to the patient's right to autonomy are justified in the period when mental conditions alter their ability to make decisions. However, as soon as he recovers, we must help him to be the decision-maker in his own choices and options.

Behind the constraints of mental illness there is a person in search of meaning and freedom, who challenges the whole team.

With this paper we intend to reflect on our daily practice, in order to promote autonomy in the act of caring, and to safeguard the respect for the patient's dignity, using humanized competence and holistic attention appropriate to each case.
\end{abstract}

Key words: Autonomy, right, patient, ethical-legal.

\title{
1 INTRODUÇÃO
}

A passividade do doente, que entrega o seu destino nas mãos dos profissionais de saúde, convencido que eles são os detentores de conhecimentos e que sabem o que é melhor para si, tem vindo a sofrer alterações. Tem sido reforçada a importância de colocar o doente no centro do processo de tomada de decisão, dando-lhe maior autonomia ou seja maior poder e controlo sobre a sua vida. No contexto atual é consensual que o cidadão deve ter uma atitude proativa, porque ele é o principal responsável pela sua saúde. Tal, só será possível, com uma informação objetiva, transparente e compreensível, que o torne apto a decidir como cidadão livre e esclarecido.

Numa perspectiva do cuidar em psiquiatria, os enfermeiros têm um papel preponderante na defesa dos direitos da pessoa, na garantia da qualidade dos cuidados que prestam e na melhoria da assistência 
psiquiátrica. No entanto, na prática diária, são confrontados com muitas tensões entre a autonomia e o bem comum, entre o respeito pela defesa dos direitos dos utentes e a justiça social e, por último, com a salvaguarda e promoção do bem-estar e proteção da pessoa que não tem capacidade para compreender quais são os seus melhores interesses.

A Organização Mundial de Saúde, ao refletir sobre esta problemática refere que por vezes pode ocorrer um conflito entre o direito do doente mental à autonomia e a obrigação da sociedade de prevenir danos às pessoas, nomeadamente, doentes que apresentam riscos a si mesmos e aos outros.

Na perspectiva do respeito pela pessoa, a autonomia incorpora pelo menos duas convicções éticas: a primeira, que os indivíduos devem ser tratados como agentes autónomos; a segunda que as pessoas com autonomia diminuída devem ser protegidas.

Constitui um dever moral dos profissionais, o respeito pela liberdade do ser humano doente, para que este reencontre o caminho de crescimento, de autonomia e de maturidade, em suma, de reencontro consigo próprio.

Os profissionais de saúde deverão conhecer a dignidade objetiva do doente mental, semelhante à da pessoa saudável. Simultaneamente, deverão conhecer e respeitar a situação subjetiva para avaliar adequadamente a sua responsabilidade e ajudar, assim, a suprir as limitações existentes.

O enfermeiro deve lidar com a pessoa como ser autónomo. Caso não seja possível, deve procurar promover a autonomia, tendo em vista o respeito pela sua dignidade, a preocupação em reabilitá-la, em melhorar a sua qualidade de vida e as suas próprias competências para lidar com o meio que a rodeia. Deve atuar como facilitador e promotor, na defesa e proteção do bem-estar bio psicossocial, tentando favorecer a aquisição do maior grau de independência, otimizando as potencialidades na melhoria da sua funcionalidade.

\section{DIREITOS DOS DOENTES}

O núcleo essencial dos direitos dos doentes é a dignidade da pessoa humana. Os direitos dos doentes devem ser respeitados por todos os profissionais envolvidos no processo de prestação de cuidados, tanto em relação aos aspectos técnicos, como aos atos de acolhimento, orientação e encaminhamento dos doentes. A" Carta dos Direitos e Deveres dos Doentes" apresenta doze direitos que a seguir se explicam em pormenor.

1. "O doente tem direito a ser tratado no respeito pela dignidade humana". Este é um direito humano fundamental, que adquire particular evidência em situação de doença.

2. “O doente tem direito ao respeito pelas suas convicções culturais, filosóficas e religiosas”. Cada doente é uma pessoa com as suas convicções culturais e religiosas. As instituições e os prestadores de 
cuidados de saúde têm, assim, de respeitar esses valores e providenciar a sua satisfação. O apoio de familiares e amigos deve ser facilitado e incentivado.

3." O doente tem direito a receber os cuidados apropriados ao seu estado de saúde, no âmbito dos cuidados preventivos, curativos, de reabilitação e terminais”. Os serviços de saúde devem estar acessíveis a todos os cidadãos, de forma a prestar, em tempo útil, os cuidados técnicos e científicos que assegurem a melhoria da condição do doente e seu restabelecimento, assim como o acompanhamento digno e humano em situações terminais.

4. “O doente tem direito à prestação de cuidados continuados”. Em situação de doença, todos os cidadãos têm o direito de obter dos diversos níveis de prestação de cuidados (hospitais e centros de saúde) uma resposta pronta e eficiente, que lhes proporcione o necessário acompanhamento até ao seu completo restabelecimento. $\mathrm{O}$ doente e seus familiares têm direito a ser informados das razões da transferência de um nível de cuidados para outro e a ser esclarecidos de que a continuidade da sua prestação fica garantida. Ao doente e sua família são proporcionados os conhecimentos e as informações que se mostrem essenciais aos cuidados que o doente deve continuar a receber no seu domicílio

5. "O doente tem direito a ser informado acerca dos serviços de saúde existentes, suas competências e níveis de cuidados." Ao cidadão tem que ser fornecida informação acerca dos serviços de saúde locais, regionais e nacionais existentes, suas competências e níveis de cuidados, regras de organização e funcionamento, de modo a otimizar e a tornar mais cómoda a sua utilização.

6. “O doente tem direito a ser informado sobre a sua situação de saúde”. Esta informação deve ser prestada de forma clara, devendo ter sempre em conta a personalidade, o grau de instrução e as condições clínicas e psíquicas do doente. Especificamente, a informação deve conter elementos relativos ao diagnóstico (tipo de doença), ao prognóstico (evolução da doença), tratamentos a efectuar, possíveis riscos e eventuais tratamentos alternativos. O doente pode desejar não ser informado do seu estado de saúde, devendo indicar, caso o entenda, quem deve receber a informação em seu lugar.

7. “O doente tem o direito de obter uma segunda opinião sobre o seu estado de saúde”. Este direito, que se traduz na obtenção de parecer de um outro médico, permite ao doente complementar a informação sobre o seu estado de saúde, dando-lhe a possibilidade de decidir, de forma mais esclarecida, acerca do tratamento a prosseguir.

8. " O doente tem direito a dar ou recusar o seu consentimento, antes de qualquer ato médico ou participação em investigação ou ensino clínico”. O consentimento do doente é imprescindível para a realização de qualquer ato médico, após ter sido corretamente informado. O doente pode, excetuando alguns casos particulares, decidir, de forma livre e esclarecida, se aceita ou recusa um tratamento ou uma intervenção, bem como alterar a sua decisão. Pretende-se, assim, assegurar e estimular o direito à autodeterminação, ou seja, a capacidade e a autonomia que os doentes têm de decidir sobre si próprios. O 
consentimento pode ser presumido em situações de emergência e, em caso de incapacidade, deve este direito ser exercido pelo representante legal do doente.

9. “O doente tem direito à confidencialidade de toda a informação clínica e elementos identificativos que lhe respeitam “. Todas as informações referentes ao estado de saúde do doente, situação clínica, diagnóstico, prognóstico, tratamento e dados de carácter pessoal, são confidenciais. Contudo, se o doente der o seu consentimento e não houver prejuízos para terceiros, ou se a lei o determinar, podem estas informações ser utilizadas. Este direito implica a obrigatoriedade do segredo profissional, a respeitar por todo o pessoal que desenvolve a sua actividade nos serviços de saúde.

10. “O doente tem direito de acesso aos dados registados no seu processo clínico.” A informação clínica e os elementos identificativos de um doente estão contidos no seu processo clínico. O doente tem o direito de tomar conhecimento dos dados registados no seu processo, devendo essa informação ser fornecida de forma precisa e esclarecedora. A omissão de alguns desses dados apenas é justificável se a sua revelação for considerada prejudicial para o doente ou se contiverem informação sobre terceiras pessoas.

11. " O doente tem direito à privacidade na prestação de todo e qualquer acto médico”. A prestação de cuidados de saúde efectua-se no respeito rigoroso do direito do doente à privacidade, o que significa que qualquer ato de diagnóstico ou terapêutica só pode ser efectuado na presença dos profissionais indispensáveis à sua execução, salvo se o doente consentir ou pedir a presença de outros elementos.

12. "O doente tem direito, por si ou por quem o represente, a apresentar sugestões e reclamações". O doente, por si, por quem legitimamente o substitua ou por organizações representativas, pode avaliar a qualidade dos cuidados prestados e apresentar sugestões ou reclamações.

\section{O PRINCÍPIO DO RESPEITO PELA AUTONOMIA INDIVIDUAL}

A palavra autonomia deriva do grego autos ("próprio") e nomos ("regra", “autoridade” ou "lei”), utilizou-se pela primeira vez como referência a auto-regulação e autogoverno das cidades-estados independentes. Atualmente, este termo também se utiliza para as pessoas e adquiriu diversos significados como: autogoverno, direito de liberdade, intimidade, decisão de ser dono de si mesmo.

Para Roque Cabral, o princípio da autonomia aplicado ao campo das ciências biomédicas, implica promover quanto possível, comportamentos autónomos por parte dos doentes, informando-os convenientemente, assegurando-lhes a correta compreensão da informação facultada e o respeito pela sua livre decisão. O autor considera que a autonomia não tem valor absoluto e o princípio que impõe o seu respeito não é incondicional, podendo ser limitado pelo respeito por outros valores ou assegurado por outros princípios como o da beneficência e da justiça. Por isso, é mais correcto falar de legítima autonomia. Assim não é o único princípio a ter em conta, devendo ser compatibilizado com outros. 
A possibilidade de que cada pessoa possa gerir a sua própria vida, passa pelo conhecimento e reconhecimento dos limites, das alternativas existentes, por uma perspetiva democrática e ética, o que implica respeito ao outro, respeito e valorização das subjetividades, saberes e valores, assim como pela impossibilidade de pensar o indivíduo como independente do coletivo

Reconhecer o valor presente na autonomia implica que esta seja suscitada, protegida, reforçada e respeitada. Promover ou defender o princípio de autonomia, exige um processo contínuo de respeito pela individualidade e originalidade do outro, pelas suas escolhas e decisões, de modo a que sejam cada vez mais autónomas ou livres. Nesta perspetiva, a nível dos direitos dos doentes ( $8^{\circ}$ direito), o principio da autonomia concretiza-se no consentimento informado - autorização autónoma dada pelo doente para uma intervenção médica e/ou pesquisa, salvaguardando sempre as condições legais por ela implicadas.

De acordo com Ana Queirós a autonomia é a capacidade de ser o seu próprio legislador, de se conduzir a si mesmo, de decidir sem se demitir, de assumir os seus próprios condicionalismos e de se apoiar neles para se tornar a pessoa que é. Este princípio de autonomia "prescreve o respeito pela legítima autonomia das pessoas, pelas suas escolhas e decisões" para além dos seus valores. Ana Queirós entende "por agir autónomo, aquele que implica intencionalidade, compreensão e ausência de influências que o determinem". Segundo a mesma autora, na prática, “o princípio de autonomia implica promover, quanto possível, comportamentos autónomos nos utentes, informando-os convenientemente, assegurando a correta compreensão da informação ministrada e a livre decisão." Podemos deste modo dizer que a "vida autónoma" não se esgota num conceito, é uma política, uma filosofia assistencial.

O respeito pela autonomia do outro, mais que a obrigação de não interferir nas decisões das pessoas, implica agir para sustentar as suas capacidades, possibilitando a escolha livre e consciente, diminuindo os temores e outras condições que possam afectar a sua autonomia. Nesta perspectiva, implica fazer o que está ao nosso alcance, de forma a capacitar a pessoa a agir autonomamente. Exige dos profissionais o dever de revelar as informações, verificar e assegurar o esclarecimento e a voluntariedade, e encorajar a tomada de decisão.

\section{OS PRINCÍPIOS DA BENEFICÊNCIA, DA NÃO MALEFICÊNCIA E DA JUSTIÇA}

A beneficência é a obrigação de garantir o bem-estar do indivíduo e a obrigação de desenvolver meios para tornar mais fácil, a sustentabilidade futura. Segundo alguns autores, o princípio da beneficência inclui o da não maleficência (princípio que determina o não infligir qualquer mal) ou, pelo menos, a obrigação, de promover positivamente o bem e evitar e remover o mal. Também indicam como pertencendo essencialmente a este princípio, a ponderação dos benefícios e dos danos. Numa perspetiva atual, trata-se de respeitar a vontade do doente na óptica do seu melhor interesse e, preferencialmente sem o prejudicar. 
O princípio da justiça refere-se à obrigação ética de dar a cada pessoa o que lhe é devido. Este princípio reclama uma distribuição equitativa (princípio da equidade) dos recursos entre os cidadãos, no que se refere a matéria sanitária, para evitar descriminação nas políticas de saúde.

\section{A AUTONOMIA DO DOENTE MENTAL}

Respeitar a liberdade e os direitos da pessoa é respeitar a sua totalidade. Este respeito à totalidade do doente mental, por vezes não pode ser praticado em toda a sua extensão. Aqueles que têm a autonomia reduzida, como no caso dos doentes mentais, devem ser tratados e protegidos de forma especial, isto é, devem ser cuidados respeitosamente.

O doente mental internado, precisa ser ouvido e compreendido na sua linguagem, muitas vezes incompreensível, que esconde o seu sofrimento. A autonomia da pessoa doente existe para além da sua capacidade de expressão, comprometida por uma doença psíquica. É necessário apreender o sentido, ao menos geral, da disposição da pessoa doente em relação ao seu processo terapêutico, sempre que este esteja em condições de o comunicar, mesmo imperfeitamente, aproveitando para tal, os momentos lúcidos e calmos da pessoa com doença mental. A aceitação da autonomia do doente é a consequência do respeito pela sua intrínseca dignidade.

Entretanto, mesmo respeitando a prerrogativa de serem todas as pessoas iguais em direitos, nem todas têm a capacidade de se autodeterminar na mesma medida. Em geral, esta capacidade amadurece durante a vida do indivíduo e algumas pessoas perdem-na total ou parcialmente devido a doenças, distúrbios mentais ou circunstâncias que severamente restrinjam a liberdade. Dado esse diferencial na capacidade de exercício da autonomia torna-se necessário considerar, nesses casos, também, os princípios da justiça e equidade, ou seja, é indispensável ter-se em conta que as diferenças relevantes que possam afetar as escolhas autónomas, devem ser ponderadas para a efetiva aplicação da justiça.

\section{O CONSENTIMENTO INFORMADO}

O direito de aceitar ou não o tratamento/ internamento é o paradigma básico da autonomia. Implica a adesão adulta, esclarecida e livre a um projecto de tratamento. Os elementos essenciais do consentimento são: a capacidade para decidir, a liberdade na decisão e a informação adequada, fornecida de acordo com a capacidade de compreensão da pessoa. O sentido e a finalidade do consentimento visa proteger a autonomia do doente face às intervenções terapêuticas propostas pela equipa. Pretende-se promover ao máximo o respeito pela pessoa doente e pela sua dignidade, de modo que ela não fique marginalizada nem diminuída devido à sua situação. Através do consentimento livre e esclarecido pretende-se que seja o próprio doente, sempre que possível, a definir o que é bom e aceitável para si mesmo. 
O conceito de autonomia implica o consentimento informado e requer capacidade racional da pessoa para compreender informações e a partir delas tomar decisões - habilidade que as pessoas mentalmente incapazes não possuem ou têm gravemente comprometida. O direito ao consentimento informado parte do pressuposto de que o utente tem a capacidade de tomar decisões, de compreender a natureza e implicações das opções que lhe são apresentadas e fazer escolhas livres. Entretanto, outros elementos são indispensáveis para escolhas conscientes além da compreensão das alternativas. Também devem ser valorizados os processos mentais que decorrem da capacidade cognitiva. A cognição é o ato ou processo de conhecer, que envolve atenção, percepção, memória, raciocínio, juízo, imaginação, pensamento e linguagem - exatamente os recursos de processamento de informações que são afetados nos distúrbios mentais.

O doente psiquiátrico pode (ou não) estar clinicamente impedido de consentir soberanamente, dado que existe a possibilidade de o distúrbio que o afeta dificultar ou impedir o uso de um ou mais atributos da cognição. Da mesma forma, ocorre com o imaturo ou aquele que por outras razões de saúde se tornou incapaz para fazer escolhas e tomar decisões. Como, mesmo em tais condições, as pessoas devem ser tratadas como seres humanos, ou seja, portadoras da dignidade inerente que se confere a todos e qualquer um, simplesmente por serem pessoas, se pode conceber que isso inclua o direito de não serem discriminadas.

Em psiquiatria, falar sobre o consentimento informado é dar ao doente, sempre que possível, o protagonismo no seu processo de tratamento e reabilitação. Não poucas vezes, este consentimento era tacitamente presumido, e a actuação do profissional considerava-se justificada pelo interesse do doente, embora prescindindo, ou mesmo contrariando a expressão da sua vontade. Atualmente, a ênfase na defesa dos direitos humanos e na sua dignidade e integridade pessoais, vieram tornar evidente que só em casos bem justificados se pode deixar de atender à vontade do doente. Daí a necessidade de se estabelecer normas de orientação claras e universais, que tenham sempre em linha de conta a individualidade da pessoa concreta e o seu processo existencial.

Segundo J. Barreto, existem diferentes capacidades para consentir relacionadas com a diversidade de perturbações. Torna-se, pois, importante averiguar os graus de capacidade para consentir e, consequentemente, formular uma escolha livre nela baseada. O reconhecimento ou não, para prestar consentimento a uma intervenção profissional, não decorre simplesmente do tipo de perturbação psíquica que afecta o doente. Também há que ter em conta a situação, a gravidade e o risco das decisões a tomar. Todas estas informações devem ser complementadas com o conhecimento da personalidade do doente, o seu nível de cultura e pressões a que está submetido. Porém, algumas vezes, o doente mental pode apresentar uma capacidade reduzida ou até mesmo nenhuma capacidade de expressar o seu consentimento consciente e responsável. Contudo, a sua vida e a sua saúde devem ser igualmente protegidas. Portanto, quando se fala em direitos do doente mental, não se pode entender a palavra "direito" apenas no seu alcance 
e significação "subjectivos", em função do consentimento; ela deve ser entendida, também, como a garantia de receber de facto cuidados para a salvaguarda de sua vida e da sua saúde. Existem situações em psiquiatria nas quais o consentimento informado não pode ser aplicado, nomeadamente nas situações de demência ou de psicose aguda e nas situações de incapacidade de expressar o próprio consentimento.

A sociedade tem a obrigação ética de tratar os seus doentes e de promover, quanto possível, a sua saúde e bem-estar. O doente psiquiátrico representa, muitas vezes, um caso especial de pessoa sem competência para decidir. Nesse momento, ele tende a rejeitar precisamente aquele tratamento que lhe poderia trazer a saúde mental. Impõe-se então, no seu interesse e no da comunidade, tratá-lo sem a sua colaboração e adesão iniciais, tornando-se necessária a sua hospitalização compulsiva. O internamento compulsivo é, assim, um recurso a que podemos aceder, por indicação jurídica, quando o doente não aceita o internamento de forma voluntária. No internamento compulsivo, a principal finalidade da pessoa que participa nos cuidados de saúde, consiste em "não causar dano". A segurança dos indivíduos e a nossa própria segurança deve ser um pensamento sempre presente ao longo da nossa vida profissional. Em Portugal, a Lei no 36/98, de 24 de Julho, denominada Lei de Saúde Mental, estabelece princípios gerais de política de saúde mental e regula o internamento compulsivo dos portadores de anomalia psíquica, designadamente de pessoas com doença mental. Podemos concluir que todo o individuo tem liberdade de decisão para recusar o tratamento ou internamento, excepto quando lhe for retirada essa liberdade por meios legais.

\section{REFLEXÃO SOBRE A AUTONOMIA DO INDIVÍDUO COM PATOLOGIA MENTAL}

O conceito de autonomia remete-nos assim, tanto para a capacidade de cada um em assumir e dirigir a sua própria vida, através de decisões livres e responsáveis, como para o comportamento em sociedade, que poderá favorecer ou limitar significativamente o exercício e o desenvolvimento da autonomia pessoal.

A prática do princípio da autonomia tem influenciado o evoluir da psiquiatria, tanto do ponto de vista legal, como moral e assistencial. O elemento decisor alterou-se indiscutivelmente. De uma tomada de decisão centrada no médico, passou-se para um leque muito mais alargado de decisores, ou seja, o doente pode contar com a equipa multidisciplinar, e sobretudo com ele próprio, como protagonista do projeto terapêutico.

Para que se possa aplicar o princípio de autonomia com rigor e idoneidade temos de falar necessariamente de competência mental. Esta entende-se como a capacidade do utente para compreender a sua situação, os valores que estão em jogo e os recursos de ação possíveis, com as consequências previsíveis de cada uma delas. Deve ainda ter competência mental para tomar, expressar e defender uma decisão que seja correta e coerente com a sua própria escala de valores. 
Não se pode negar a competência de uma pessoa pelo simples fato de estar doente, ou pelo fato da avaliação obtida definir que a competência depende das suas capacidades mentais, que podem estar mais ou menos alteradas. Por essa pessoa ter mais ou menos dificuldade para determinadas opções, não nos deve levar a concluir que é incapaz para todas.

O princípio da autonomia nos doentes psiquiátricos traz consigo muitos mais problemas, nomeadamente nos doentes que não têm consciência da sua doença e, como tal, não recorrem ao médico. Se o fazem é, na maior parte das vezes, por vontade de outrem.

O princípio da autonomia impõe o respeito pela pessoa, entendendo-se esta como um ser humano. Quem tem problemas psiquiátricos não é excepção a esta regra. Defender e promover a autonomia da pessoa com problemas psiquiátricos é, cada vez mais, um desafio que implica determinação, facilitando comportamentos autónomos, prestando toda a informação possível de forma clara, de modo que ele possa decidir livremente sem se sentir coagido na sua escolha.

Falar de autonomia do doente psíquico, exige-nos uma profunda reflexão em relação às inumeráveis situações no assistir e cuidar psiquiátrico. De facto, a relação entre o direito e a psiquiatria é sem sombra de dúvida um progresso na história da assistência psiquiátrica. No entanto, na nossa intervenção, confrontamo-nos muitas vezes com a problemática de como tratar com os limites do princípio de autonomia, e de como resolver as complexas situações que encontramos entre a liberdade e a responsabilidade, entre os direitos e os deveres.

Várias são as vezes que nos questionamos acerca da autonomia do utente que se encontra em internamento/ tratamento compulsivo, pois, após esta pequena revisão bibliográfica, podemos concluir que se o doente está em regime de internamento/tratamento compulsivo, deve-se na maior parte das vezes ao não reconhecimento da sua doença e à consequente adesão ao regime terapêutico.

Assim, quando se atribui um nível de autonomia ao doente mental, têm de avaliados os seus limites para evitar negligenciar o seu estado de saúde e o de terceiros. A alteração da percepção e do conhecimento poderão reflectir decisões e atitudes erróneas para os quais não é portador de juízo de censura.

Frequentemente, existe confronto entre o princípio da beneficência e da autonomia, ou seja, entre o dever de responder às necessidades assistenciais do doente e o seu direito de exercício de liberdade pessoal. Muitas vezes, um doente recusa determinado tratamento que poderia beneficiá-lo. Se a comunidade ou ele próprio estão ameaçados por comportamentos violentos, o princípio da não maleficência ganha precedência sobre a revindicação da sua autodeterminação. A comprovada incapacidade de se cuidar, também justificaria uma restrição da sua liberdade. Caso contrário, qualquer tratamento imposto consiste numa violação injustificada da sua autonomia. Outras vezes, o doente pode aceitar facilmente o tratamento pelo seu médico, tornando-se ele próprio o autor da sua própria história de cura e/ou reabilitação. 
A legitimidade de uma decisão, exige que ela seja informada, voluntária, competente e sem juízos de valor. Exige que seja explicado à pessoa as diferentes opções, esperando que tome a decisão que achar melhor. Se a pessoa madura é caracterizada pela autoconsciência, pela responsabilidade, pela autonomia e pelo respeito à pessoa do outro, o agir do profissional será ético na medida em que procura suscitar a autonomia, a liberdade, a responsabilidade do sujeito, defendendo-as e promovendo-as quando e na medida em que o indivíduo não tiver possibilidade de autodeterminação.

\section{CONCLUSÃO}

A doença psiquiátrica, enquanto realidade que afecta as raízes mais profundas da existência do indivíduo, afecta a globalidade do ser, na medida em que torna vulnerável a sua integridade, as suas capacidades e autonomia. A doença mental, qualquer que seja, mas sobretudo a de evolução prolongada, afecta a pessoa na sua globalidade e instaura uma complexa dinâmica, não só no sentido patológico, mas também em sentido existencial. Daí que não deve ser abordada apenas clinicamente, antes, deverá ser interpretada na envolvência da história pessoal, familiar e social do indivíduo.

A vivência de uma situação de doença mental, está muitas vezes afectada por um estigma e consequentemente por um isolamento social, ao qual, o doente é progressivamente submetido durante a sua experiência existencial com a patologia. Esta estigmatização assume proporções e características que influenciam de forma determinante a qualidade de vida destas pessoas, sendo para elas muitas vezes o desabar das suas relações familiares e sociais.

No contexto promotor de autonomia, a pessoa, a família e o contexto social são realidades intrinsecamente interligadas, que consequentemente têm que fazer parte do dinamismo reabilitador. Se assim não for, pouco ou nada se poderá fazer. Só nesta envolvência é possível desenvolver um projecto, que visa a melhoria da qualidade de vida da pessoa com doença mental. Ajudar a pessoa com doença mental a passar do seu isolamento para uma atitude participativa, para um caminho de descoberta da sua autonomia e capacidade de decisão, é um desafio constante que permanece no assistir psiquiátrico.

A autonomia é o fundamento da dignidade humana de todo o ser racional. É na expressão de sua autonomia que o ser humano se dignifica, não devendo ser restringida, a pretexto de substituir a livre vontade, por aquilo que se acredita ser o melhor ou mais apropriado. Pessoas vulneráveis, como os portadores de distúrbios mentais, estão entre os mais sujeitos a abusos que violam este atributo de sua dignidade.

Constata-se que, o limite entre a retirada do poder/autonomia justificado com a situação clínica, e a imposição desrespeitosa de força, com a finalidade de garantir maior comodidade por quem detêm o poder, é muito ténue. 
O agir ético é, portanto, o constante exercício de identificar como e quando é mais fácil desrespeitar a dignidade e evitar fazê-lo. 


\section{BIBLIOGRAFIA}

ELIZARI, Francisco - Questões de Bioética: vida em Qualidade. Porto: Ed. Perpétuo Socorro, 1996, p.241-243.

BARRETO, João - Doença Psíquica. Bioética, Porto: Editora Verbo, 1996, p.319-320.

CABRAL, Roque - "Princípio de autonomia” In ARCHER, Luís (et. All) - “Bioética”, p.54.

QUEIRÓS Ana Albuquerque - “Ética e Enfermagem” 1ª Edição. Coimbra: Quarteto Editora, 2011, p.57.

BEAUCHAMP, T; CHILDRESS, - Princípios de Ética Biomédica”, p.142 -145.

JOSEP Ma LLOVET HAYA - "La competencia mental: concepto e evaluacion, in: Labor Hospitalaria, Barcelona, 2-2002, No 264, Vol.XXXIV, p. 91.

MIRANDA P. M. Alexandra (2010) - Importância atribuída pelos enfermeiros ao empowerment do doente na relação terapêutica enfermeiro / doente - Dissertação para a obtenção do grau de mestre em comunicação em saúde, especialidade em intervenção em enfermagem, Universidade Aberta de Lisboa. P. $18-21$.

COELHO Rui, RAMOS Sónia (2005) - Aspectos éticos da saúde mental (parte I) - Cadernos de Bioética, Edição do Centro de Estudos de Bioética, p. 176 -177. 